\title{
AVALIAÇÃO CLÍNICA E IMUNOLÓGICA DE CRIANÇAS E ADOLESCENTES HIV-POSITIVOS DE FERNANDÓPOLIS
}

\author{
ARTIGO ORIGINAL \\ PIROLA, Isabela Gonçalves ${ }^{1}$ \\ REIS, Isabella Cristina Sabino dos ${ }^{2}$ \\ GAGGINI, Márcio Cesar Reino ${ }^{3}$
}

PIROLA, Isabela Gonçalves. REIS, Isabella Cristina Sabino dos. GAGGINI, Márcio Cesar Reino. Avaliação Clínica e Imunológica de Crianças e Adolescentes HIVpositivos de Fernandópolis. Revista Científica Multidisciplinar Núcleo do Conhecimento. Ano 05, Ed. 01, Vol. 08, pp. 162-182. Janeiro de 2020. ISSN: 24480959, Link de acesso: https://www.nucleodoconhecimento.com.br/saude/avaliacaoclinica

\section{RESUMO}

Introdução: O curso clínico da infecção pelo HIV em crianças não é o mesmo para todos os pacientes, variando entre progressores rápidos, normais e lentos. Enquanto os progressores rápidos evoluem com quadros graves no primeiro ano de vida,

\footnotetext{
${ }^{1}$ Graduanda em medicina, Universidade Brasil.

${ }^{2}$ Graduanda em medicina, Universidade Brasil.

${ }^{3}$ Mestrado em Bioengenharia pela Universidade Brasil. Título de Área de Atuação em Hansenologia pela Associação Médica Brasileira. Título de Área de Atuação em Medicina Tropical pela Associação Médica Brasileira. Título de Especialista em Infectologia pela Sociedade Brasileira de Infectologia. Título de Especialista em Clínica Médica pela Sociedade Brasileira de Clínica Médica. Residência em Infectologia pela Faculdade de Medicina de Marília. Graduação em Medicina pela Faculdade de Medicina de Catanduva (1997).
} 
podendo morrer antes dos quatro anos; a progressão normal é mais lenta, com sintomas que podem se iniciar na idade escolar ou adolescência, com sobrevida de nove a dez anos. Já os progressores lentos não apresentam depleção significativa de células CD4+ e nem manifestações clínicas da AIDS por 8 anos ou mais após a infecção, possuindo progressão mínima ou nula. A avaliação imunológica, portanto, é um instrumento importante, visto que afere o dano causado pelo HIV ao sistema imune do paciente. Objetivo: Este estudo tem como objetivo analisar o perfil epidemiológico, clínico, imunológico e virológico das crianças e adolescentes HIV-positivas da microrregião de Fernandópolis-SP, de forma a correlacionar com a literatura científica. Metodologia: Trata-se de um estudo retrospectivo baseado em informações coletadas dos prontuários dos pacientes do Centro de Atendimento de Doenças Infecciosas e Parasitárias de Fernandópolis, correlacionando-as com as referências bibliográficas. Resultados: A etiologia da doença foi principalmente por transmissão vertical. As faixas etárias mais prevalentes de início da terapia antirretroviral variaram entre 8 meses e 17 anos, sendo a lamivudina o medicamento mais utilizado, predominantemente no esquema com a zidovudina, lopinavir e ritonavir. O período mais comum de início terapêutico caracterizou-se por quadros onde já havia alterações imunológicas significativas, entretanto, de acordo com estudos, o controle precoce da doença, mesmo em assintomáticos, é essencial para redução da morbimortalidade. A maioria dos pacientes já foram internados, sendo as infecções mais prevalentes as de vias aéreas superiores. Conclusão: Através deste estudo, conclui-se que a forma de transmissão mais prevalente em crianças e adolescentes foi a vertical, ficando evidente a necessidade de políticas públicas eficazes que incentivem a conscientização, a prevenção e/ou tratamento das DST'S, além do acompanhamento pré-natal regular associado a um parto seguro e ao uso correto dos antirretrovirais.

Palavras-chave: Crianças e Adolescentes, HIV.

\section{INTRODUÇÃO}

Segundo o Ministério da Saúde, no Brasil, foram notificados 656.701 casos de AIDS de 1980 a junho de 2012, sendo 17.539 desses casos em menores de 5 anos, e 4.435 
em crianças entre 5 e 9 anos. ${ }^{1}$ No ano de 2015, de acordo com o Boletim Epidemiológico de HIV do Ministério da Saúde, 93\% dos indivíduos menores de 13 anos HIV positivos tiveram como via de infecção a transmissão vertical, enquanto que apenas $7 \%$ correspondem à transmissão sexual e sanguínea. ${ }^{2} \mathrm{~A}$ transmissão vertical consiste na passagem do vírus da mãe para o filho, sendo que $65 \%$ dos casos ocorrem no parto, $35 \%$ na gestação e entre $7 \%$ e $22 \%$ com o aleitamento materno. ${ }^{3}$ Já em adolescentes (13 anos ou mais) prevaleceu a transmissão sexual, tanto em homens $(95,3 \%)$ quanto em mulheres $(97,1 \%)$. Observa-se também no país, no período de 2006 a 2015, um aumento de $28,6 \%$ na taxa de detecção de HIV em gestantes, diferentemente dos casos de transmissão vertical, que tiveram uma importante queda de $42,7 \% .^{2}$ Todavia, apesar dessa redução, é possível verificar através do protocolo do Ministério, que nos últimos anos, os valores tem se estabilizado em patamares insatisfatórios, em torno de 500 casos/ano em menores de 5 anos de idade. O gráfico 1 abaixo mostra a progressão dos casos de aids em pacientes menores de 5 anos, entre 5 e 9 anos e entre 10 e 14 anos no período de 2001 a 2012.1

Gráfico 1 - Número de casos de aids, notificados no SINAN, declarados no SIM e registrados no SISCEL/SICLOM, por idade e ano de diagnóstico. Brasil, 2001 - 2012

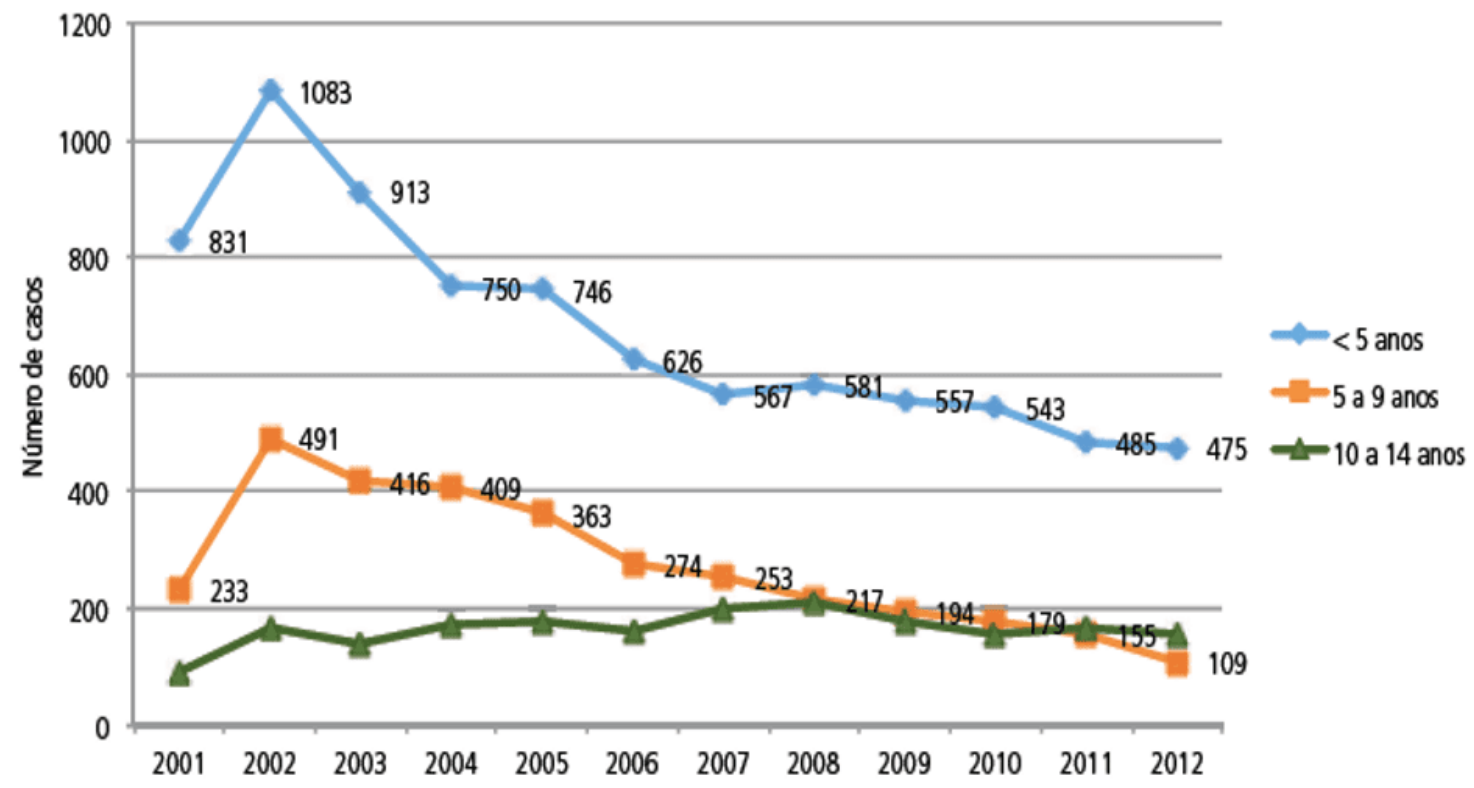

Fonte: Ministério da saúde, 2014 
Segundo Negra, Queiroz e Lian, o contágio pelo HIV causa destruição de células imunológicas, principalmente os linfócitos TCD4+, além de macrófagos e monócitos. ${ }^{4}$ Esta doença é marcada por quatro fases clínicas: infecção aguda; fase assintomática, também chamada de latência clínica; fase sintomática inicial ou precoce e Aids. ${ }^{3} \mathrm{Na}$ primeira fase, a replicação do HIV ocorre sem impedimento, aumentando, assim, rapidamente a carga viral a valores maiores que 30 milhões nas crianças, nos primeiros meses de vida. ${ }^{4}$ Por conseguinte, o pico de viremia leva a uma queda rápida dos linfócitos T CD4+, que posteriormente se elevam, mas dificilmente regressam aos valores prévios ao contágio. Ocorre também aumento dos linfócitos T CD8+ circulantes, resultando na inversão entre $C D 4+/ C D 8+$, relação, esta, que se torna menor que um. As manifestações clínicas podem variar, desde sintomas de infecção viral (febre, adenopatia, faringite, mialgia, artralgia, perda de peso, náuseas, vômitos, rash cutâneo maculopapular eritematoso, ulcerações envolvendo mucosa oral, esôfago e genitália, hiporexia, adinamia, cefaleia, fotofobia, hepatoesplenomegalia), até candidíase oral e alterações neurológicas, tais como: neuropatia periférica, meningoencefalite asséptica e síndrome de Guillain-Barré. A parte laboratorial envolve: linfopenia com subsequente linfocitose, além de linfócitos atípicos, plaquetopenia e aumento sérico das enzimas hepáticas. ${ }^{5}$ De acordo com Negra, Queiroz e Lian, com o aparecimento da resistência do organismo, a replicação viral cai e o sistema imunológico tende a manter o equilíbrio entre o agente viral e o hospedeiro, entrando assim no período de latência. ${ }^{4}$ Entretanto, embora essa fase seja assintomática, alguns indivíduos podem cursar com uma linfoadenopatia generalizada persistente, flutuante e indolor. ${ }^{5}$ Já a fase sintomática inicial, conforme dados do Ministério da Saúde, caracteriza-se por sudorese noturna, fadiga, emagrecimento, diarreia, sinusopatias, candidíase oral e vaginal, leucoplasia pilosa oral, gengivite, úlceras aftosas, herpes simples recorrente, herpes zoster e trombocitopenia. ${ }^{5} \mathrm{~A}$ cronicidade da doença leva à depleção das células CD8+, pela constante apoptose, além da perda da capacidade de reconhecimento dos antígenos específicos, diminuindo, assim, o controle da infecção a ponto de levar o sistema imune a exaustão. ${ }^{4}$ Com o avanço da infecção, o extermínio contínuo do sistema de defesa, resulta em fibrose e destruição irreversíveis dos tecidos linfoides, reduzindo, assim, os valores de linfócitos T CD4+ e T CD8+ em níveis incompatíveis com a vida, 
levando à hipogamaglobulinemia, isto é, redução das imunoglobulinas. ${ }^{4} \mathrm{E}$ então, uma vez instalada a Aids, os portadores do HIV, devido essa deficiência imunológica tanto celular quanto humoral, passam a desenvolver doenças oportunistas, que podem ser causadas por vírus (citomegalovirose, herpes simples, leucoencafalopatia multifocal progressiva), bactérias (micobacterioses, pneumonias, salmonelose), protozoários (toxoplasmose, criptosporidiose, isosporías), fungos (pneumocistose, candidíase, criptococose, histoplasmose) e certas neoplasias (sarcoma de Kaposi, linfomas nãoHodgkin, neoplasias intra-epiteliais anal e cervical). ${ }^{5}$ É possível verificar se o paciente apresenta ou não uma alteração imunológica moderada ou severa, através da contagem de células imounológicas T CD4+ (citometria de fluxo), sendo os valores mostrados na tabela 1 abaixo, baseada na classificação do CDC (Centro de Controle de Doenças):

Tabela 1 - Categorias Imunológicas da classificação da Infecção pelo HIV em crianças e adolescentes - CDC (Centro de Controle de Doenças)

\begin{tabular}{|c|c|c|c|}
\hline \multirow[t]{2}{*}{$\begin{array}{l}\text { Alteração } \\
\text { Imunológica }\end{array}$} & \multicolumn{3}{|c|}{$\begin{array}{l}\text { Idade } \\
\text { Contagem de T CD4+ (citometria de fluxo) }\end{array}$} \\
\hline & $\begin{array}{lr}< & 1 \\
\text { ano } & \left(\text { cels } / \mathrm{mm}^{3}\right)\end{array}$ & $\begin{array}{l}1 \mathrm{a}<6 \text { anos } \\
\left(\mathrm{cels} / \mathrm{mm}^{3}\right)\end{array}$ & $\begin{array}{lr}\geq & 6 \\
\text { anos } & \left(\text { cels } / \mathrm{mm}^{3}\right)\end{array}$ \\
\hline Ausente/sem & $\geq 1.500(\geq 25 \%)$ & $\begin{array}{l}\geq 1.000 \\
(\geq 25 \%)\end{array}$ & $\geq 500(\geq 25 \%)$ \\
\hline Moderada & $750-1499(15-24 \%)$ & $\begin{array}{l}500-999(15- \\
24 \%)\end{array}$ & $200-499(15-24 \%)$ \\
\hline Grave & $<750(<15 \%)$ & $<500(<15 \%)$ & $<200(<15 \%)$ \\
\hline
\end{tabular}

Fonte: Ministério da saúde, 2018 apud VAJPAYEE et al., $2005^{6}$

Segundo o protocolo do Ministério da Saúde, o curso clínico da infecção pelo HIV em crianças não é o mesmo para todos os pacientes, variando entre progressores rápidos, normais e lentos. Cerca de $20 \%$ a $30 \%$ das crianças não tratadas apresentam progressão rápida, evoluindo com sintomas graves no primeiro ano de vida, podendo 
vir a óbito antes dos quatro anos. ${ }^{6}$ Tais pacientes apresentam rápida depleção de células CD4+ e podem apresentar hipo ou agamaglobulinemia. ${ }^{7}$ Já a progressão normal, é mais lenta, e abrange $70 \%$ a $80 \%$ dos casos, sendo que as manifestações podem surgir na idade escolar ou na adolescência, com sobrevida de nove a dez anos. ${ }^{6} \mathrm{E}$ por fim, os progressores lentos (menos de $5 \%$ das crianças) são aqueles que não apresentam queda significativa de linfócitos T CD4+ e nem sintomas clínicos da AIDS por 8 anos ou mais após o contágio, possuindo uma progressão mínima ou até mesmo nula da doença. Estes indivíduos, provavelmente, herdaram particularidades genéticas que Ihes proporcionam maior resistência ao HIV e/ou estão infectados por cepas virais de baixa virulência. ${ }^{7}$

A avaliação imunológica, portanto, é um recurso importante, visto que, mensura o dano causado pelo HIV ao sistema de defesa do paciente, sendo que o aumento das imunoglobulinas e a queda de linfócitos T CD4+ são dados frequentes na AIDS pediátrica. ${ }^{7}$ Além disso, as variações imunológicas mais precoces e marcantes dessa doença em crianças envolve a imunidade humoral, tais como: aumento de linfócitos $B$, hipergamaglobulinemia policlonal e déficit na produção de anticorpos específicos. O comprometimento dos linfócitos B é explicado pela elevação de interleucina-6 (IL6) e fator de necrose tumoral alfa (TNF- $\alpha$ ), isto é, citocinas inflamatórias estimuladas pelo HIV. E as classes de imunoglobulinas aumentadas podem ser: $\lg G, \lg \mathrm{A}, \lg \mathrm{M}$ e $\operatorname{lgE}$, mas não necessariamente todas. ${ }^{7}$ Mais um marcador importante para 0 prognóstico da doença é a contagem de linfócitos T CD8+ citotóxicos, uma vez que o aumento deles está relacionado à baixa replicação viral e maior sobrevida. ${ }^{7}$ Outro artifício de resistência frente a doença é a produção de anticorpos, que ajudam a conter a replicação viral. As pessoas com resposta imunológica predominantemente celular - T helper tipo 1, com altas taxas de interleucina-2, interleucina-12 e interferongama, progridem mais lentamente para a doença; enquanto aqueles que apresentam imunidade predominantemente humoral, padrão T helper tipo 2, com elevados níveis de imunoglobulinas e interleucinas 4, 5, 6 e 10, evoluem mais rapidamente para a doença. ${ }^{4}$ 
Tendo em vista a importância da temática em questão, o presente estudo propõe avaliar o perfil epidemiológico, clínico, imunológico e virulógico das crianças e adolescentes HIV-positivas da microrregião de Fernandópolis-SP, de forma a correlacionar com a literatura científica.

\section{MATERIAL E MÉTODOS}

\subsection{DELINEAMENTO DA PESQUISA E ASPECTOS ÉTICOS}

Trata-se de um estudo epidemiológico retrospectivo observacional, realizado no período de maio de 2019 a agosto de 2019, com base nas informações coletadas dos prontuários dos pacientes do Centro de Atendimento de Doenças Infecciosas e Parasitárias (CADIP) de Fernandópolis, de forma a correlacioná-las com a literatura científica.

Após encaminhamento da documentação e autorização pelo Diretor do Campus da Universidade Brasil de Fernandópolis e pela Gerente Técnica do CADIP de Fernandópolis, o projeto foi encaminhado ao Comitê de Ética em Pesquisa (CEP) da Universidade Brasil, conforme Resoluções 196/96 e 466/12 do Conselho Nacional de Saúde. Desta forma, garantindo que todos os preceitos éticos desta legislação vigente sejam seguidos, este trabalho foi aprovado no referido órgão no ano de 2019 (CAAE: 95788517.3.0000.5494).

\subsection{POPULAÇÃO E AMOSTRA}

A população do estudo foram as crianças e adolescentes HIV-positivas que fizeram ou ainda fazem tratamento no Centro de Atendimento de Doenças Infecciosas e Parasitárias (CADIP), situado à Av. Brasília, número 756, Fernandópolis-SP. Trata-se de uma amostra de 9 pacientes que apresentam a doença, isto é, 5 crianças e 4 adolescentes, envolvendo faixas etárias entre 8 meses e 17 anos, de ambos os sexos. 


\subsection{CRITÉRIOS DE INCLUSÃO E EXCLUSÃO}

Encaixam-se no critério de inclusão as crianças e adolescentes HIV-positivas da microrregião de Fernandópolis-SP, que fizeram acompanhamento no CADIP da cidade.

Não há critérios de exclusão.

\subsection{INSTRUMENTO DE COLETA DE INFORMAÇÕES DOS PRONTUÁRIOS E ANÁLISE DOS DADOS}

Os dados obtidos dos prontuários foram baseados em um instrumento de coleta de informações elaborado pelos próprios pesquisadores para nortear a pesquisa.

As variáveis analisadas, baseadas em tal instrumento, foram: características demográficas, informações gestacionais maternas, além das condições clinicas, laboratoriais e terapêuticas dos pacientes. A parte demográfica envolveu: data de nascimento, idade e faixa etária. Com relação às gestações maternas, foi investigado: a realização correta do pré-natal, medicamentos usados durante a gravidez, tipos de parto e patologias/infecções da mãe. Enquanto que as variáveis relacionadas aos pacientes foram: a idade de início terapêutico, o esquema medicamentoso de escolha para o HIV, os valores de CD4+ e de carga viral antes e após iniciarem o tratamento, além das internações e infecções associadas ao quadro.

Os dados coletados tiveram as suas respostas agrupadas e apresentadas em gráficos, sendo correlacionados com a literatura científica.

\subsection{REVISÃO LITERÁRIA}

A revisão literária foi embasada em artigos obtidos no banco de dados do google acadêmico e da Scielo (Scientific Eletronic Library Online), além dos protocolos do Ministério da Saúde, UNAIDS e do livro Tratado de Infectologia VERONESI-FOCACCIA (vide referências bibliográficas). 


\section{RESULTADOS E DISCUSSÃO}

Ao longo da pesquisa foram analisados os dados dos prontuários de 5 crianças e 4 adolescentes, hiv-positivos, equivalendo a um total de 9 indivíduos entre 8 meses e 17 anos de idade, que fizeram ou ainda fazem tratamento no Centro de Atendimento a Doenças Infectocontagiosas e Parasitárias (CADIP) de Fernandópolis. A etiologia da doença, em 8 pacientes foi por transmissão vertical, o que corresponde a 88,8\% dos casos, enquanto apenas 1 paciente $(11,1 \%)$ a adquiriu por transmissão sexual. Esse dado é semelhante ao da literatura, que confirma que,

[...] a transmissão do HIV da mãe para o filho representa a forma mais comum de aquisição do vírus pelas crianças, podendo ocorrer intraútero, durante o trabalho de parto ou pela amamentação, afetada por vários fatores, como o estágio de infecção da mãe, idade materna, duração e tipo de parto. ${ }^{8}$

Entretanto, de todos os pacientes, 5 (55,5\%) deles não apresentavam no prontuário nenhuma informação a respeito da gestação da mãe. Já os $4(44,4 \%)$ restantes, apresentaram alguns dados de suas mães, porém incompletos, dos quais, 2 delas $(22,2 \%)$ não realizaram o pré-natal, 1 delas $(11,1 \%)$ não possuía dados a respeito, e a última $(11,1 \%)$, teve o pré-natal realizado corretamente, porém o exame anti-HIV deu negativo, sendo uma das explicações a possibilidade de que ela estava no período de janela imunológica da doença. Além disso, 11,1\% dos partos foi cesárea e $11,1 \%$ foi parto normal, não havendo informações a respeito da porcentagem restante. Outros dados analisados foram as infecções ou patologias durante a gestação, entretanto apenas uma mãe continha essa informação, apresentando herpes zoster. Já os medicamentos utilizados por elas não foram citados nos prontuários. Através dessa pesquisa, foi possível concluir que toda essa falta de informações a respeito das mães se deve ao fato de que $22,2 \%$ delas não se tratam no CADIP, enquanto que $55,5 \%$ já faleceram cujas causas de morte variam entre acidentes, suspeita de uso de drogas, infecções adquiridas após o contagio com o HIV, e até mesmo causas não mencionadas. 
Tais dados nos alertam para a importância da realização do acompanhamento prénatal regularmente associado a um parto seguro e ao "uso dos antirretrovirais de forma correta na gestação, parto e pós-parto", com o intuito de se eliminar a transmissão perinatal da doença como problema de saúde pública. Os antirretrovirais reduzem a replicação viral, diminuindo, portanto, a carga virológica e a transmissão maternoinfantil, sendo que "nos países desenvolvidos, o uso desta terapia reduziu a transmissão vertical para aproximadamente $2 \%$, na ausência de amamentação." Já em países mais pobres ou em desenvolvimento, como o Brasil, o aleitamento materno constitui um importante fator na taxa de transmissão perinatal, sendo a sua troca pelo aleitamento artificial responsável pela redução de 16,2\% das transmissões verticais, o que ressalta a importância também de apropriadas práticas de alimentação infantil. ${ }^{8}$

Com relação ao tratamento antirretroviral (TARV) entre as crianças e os adolescentes deste estudo, as faixas etárias de início terapêutico variaram de 8 meses a 17 anos, sendo os períodos mais prevalentes: de 5 a 9 anos e de 15 a 20 anos, com 3 pacientes $(33,3 \%)$ em cada intervalo. Neste primeiro intervalo, se encontram: 1 criança de 5 anos e 2 de 9 , sendo esta, a idade mais frequente de início terapêutico. Já no segundo período, se encontram: 3 adolescentes de 15, 16 e 17 anos. Enquanto os períodos menos prevalentes são: abaixo de 1 ano, entre 1 e 4 anos, e entre 10 e 14 anos, contendo todos eles apenas 1 paciente, cujas idades são: 8 meses, 2 anos e 13 anos, respectivamente (gráfico 2).

Gráfico 2 - Número de Crianças que Iniciaram o Tratamento Antirretroviral (TARV) em cada faixa etária

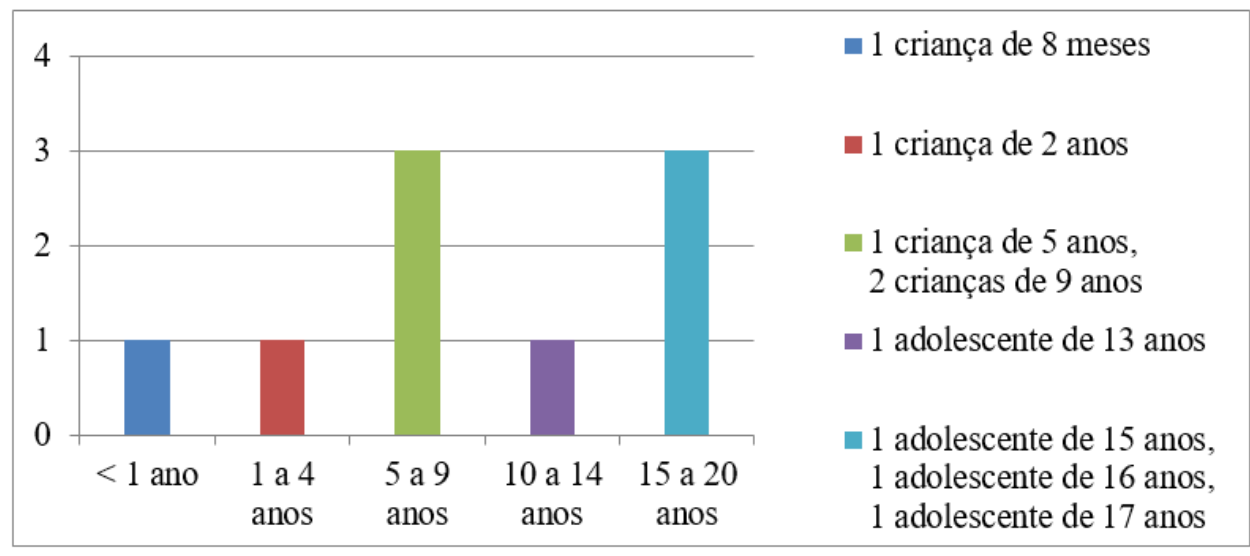

RC: 43733

Disponível em: https://www.nucleodoconhecimento.com.br/saude/avaliacao-clinica 
Fonte: Produção própria

A terapia antirretroviral (TARV) dos pacientes envolve diferentes medicamentos, tais como: efavirenz (EFZ), zidovudina (AZT), lamivudina (3TC), lopinavir (LPV), ritonavir (RTV), tenofovir (TDF) e estavudina (D4T), variando as combinações de acordo com o quadro de cada indivíduo. Dentre estes, o medicamento mais utilizado, de modo geral, foi a lamivudina, fazendo parte do esquema terapêutico de $100 \%$ dos pacientes; seguido da zidovudina, com $66,6 \%$ de indicação. Em terceiro lugar, com $55,5 \%$ veio a combinação do lopinavir com ritonavir; na sequência, com 33,3\%: o efavirenz, e com 22,2\%: o tenofovir. E por fim, os de menores frequências de uso, foram: a estavudina, e o ritonavir, com $11,1 \%$ de uso cada (gráfico 3 ).

Gráfico 3 - Porcentagem do Uso dos Medicamentos da Terapia Antirretroviral pelos Pacientes

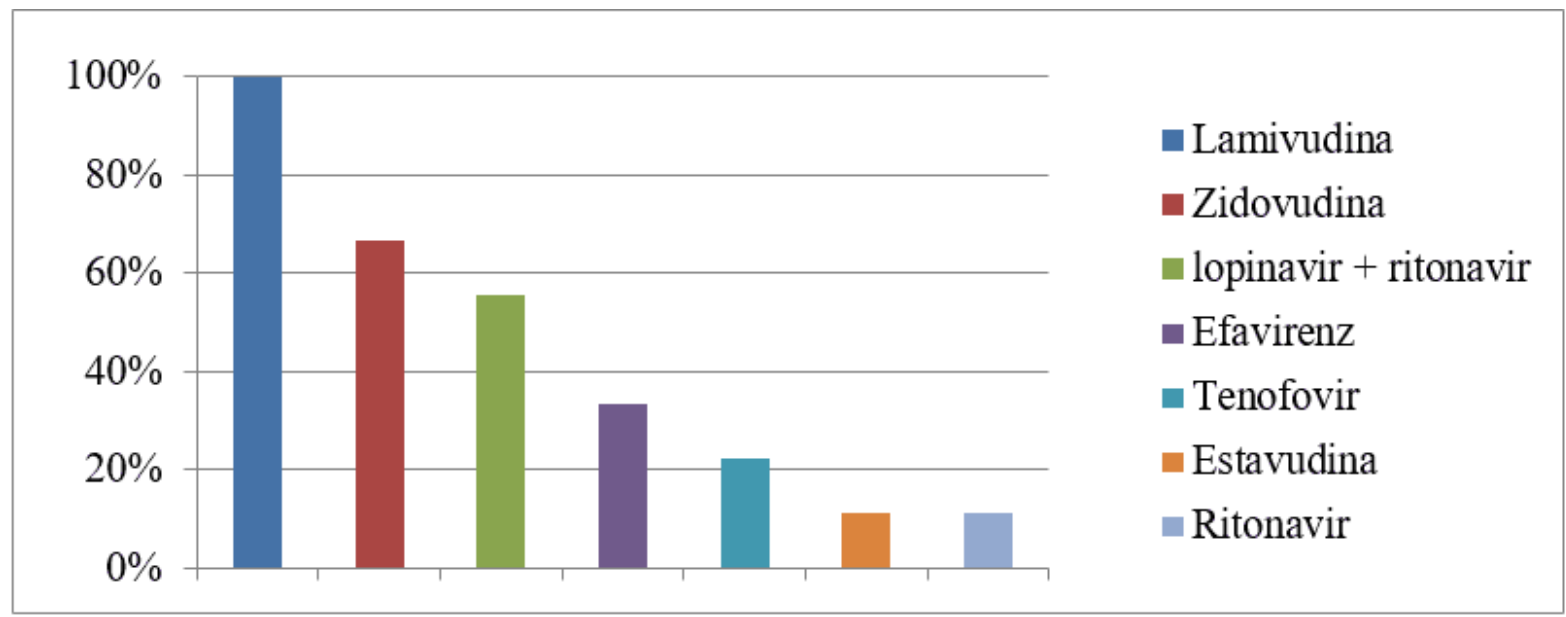

Fonte: Produção própria

Entretanto, estes medicamentos geralmente não são utilizados sozinhos, e sim, combinados com mais medicamentos, a fim de se obter um melhor resultado terapêutico. Diante disso, a combinação mais utilizada pelos pacientes foi de zidovudina com lamivudina e lopinavir/ritonavir, equivalendo a 44,4\% dos tratamentos, ou seja, 4 indivíduos. Outro esquema frequentemente utilizado é o de efavirenz combinado com zidovudina e lamivudina, que envolveu $22,2 \%$ dos tratamentos (2 pacientes). E por fim, as combinações menos usadas são: lamivudina com ritonavir e 
estavudina; lamivudina com efavirenz e tenofovir; e lamivudina com tenofovir e lopinavir/ritonavir, sendo estes três esquemas indicados apenas para um paciente cada, abrangendo cada esquema $11,1 \%$ dos tratamentos (gráfico 4).

Gráfico 4 - Quantidade de Pacientes, em Porcentagem, que Faz Uso de Cada Esquema de Tratamento Antirretroviral.

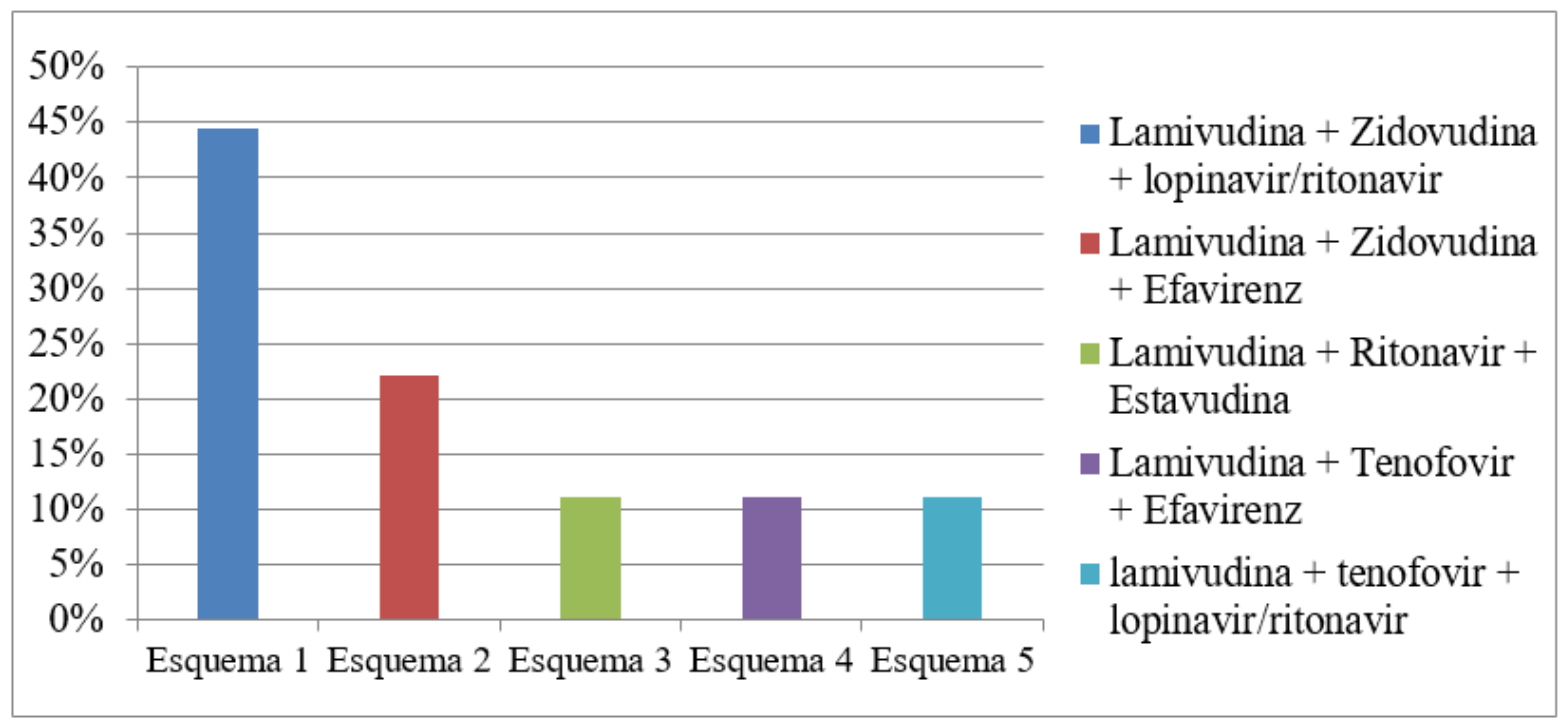

Fonte: Produção própria

Foi analisada também a última dosagem tanto de linfócitos T CD4+ quanto de carga viral de cada paciente antes e após iniciarem o tratamento. Antes da TARV, a média total obtida entre os valores de CD4+ de cada indivíduo foi de 335,7778 células, sendo o menor valor 120 e o maior 617 (gráfico 5). 
Gráfico 5 - Valores de Linfócitos T CD4+ de Cada Paciente por Ordem Crescente de Idade Antes do Início da Terapia Antirretroviral

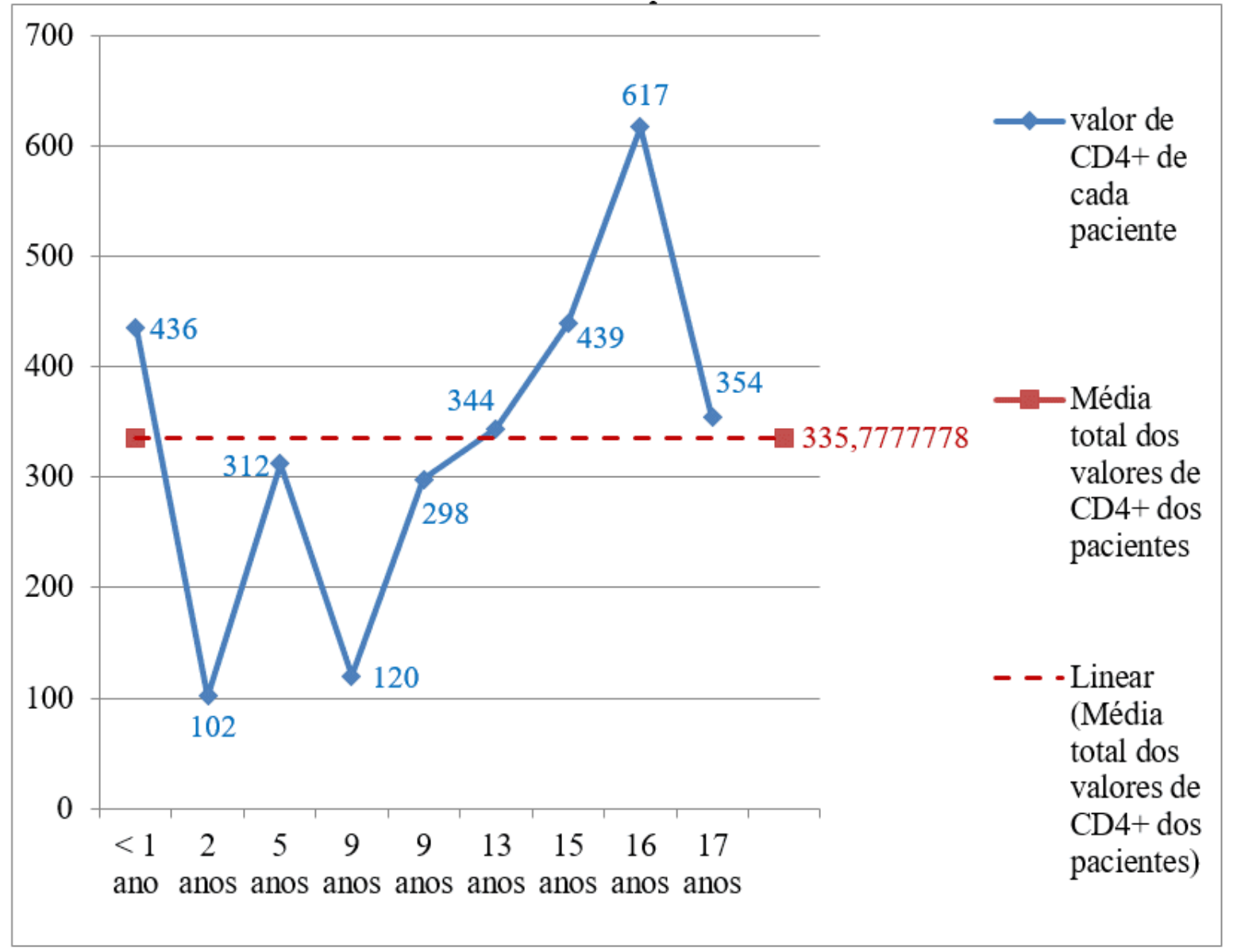

Fonte: Produção própria

Através dos valores acima, conclui-se que o período mais comum de início terapêutico caracterizou-se por quadros onde já havia alterações imunológicas significativas; uma vez que 4 pacientes entre 0 a 5 anos se encontravam em estado grave, com taxas de CD4+ abaixo de 500 cels $/ \mathrm{mm}^{3}$, e 4 pacientes acima de 6 anos se encontravam em estado moderado com níveis de CD4+ entre 200 a 499 células, ambos os casos com valores imunológicos abaixo do esperado. Isto é, aproximadamente, $88,8 \%$ dos pacientes já apresentavam alterações imunológicas, com exceção de um paciente $(11,1 \%)$, que ainda apresentava taxas normais de células CD4+. Entretanto, esperar a imunidade do paciente cair para iniciar o tratamento antirretroviral, é algo que vai contra o protocolo do Ministério de Saúde de 2018, o qual defende que tal terapia 
"deve ser indicada para todas as crianças e adolescentes vivendo com HIV, independentemente de fatores clínicos, da contagem de linfócitos T CD4+ e da carga viral de HIV." Tal argumentação se deve ao estudo START, que "demonstrou forte evidência dos benefícios na redução da morbimortalidade quando instituída a TARV precocemente." ${ }^{6} 9$ Outros estudos também defendem o início terapêutico precoce, uma vez que "a manutenção da replicação viral pode acarretar inflamação persistente e desenvolvimento de doença cardiovascular, renal e hepática, além de outras malignidades". ${ }^{6}$ Logo, o controle prévio do HIV, pode não somente preservar o sistema imune do paciente, como também diminuir a mortalidade infantil precoce e prevenir a progressão da doença. ${ }^{6,10}$

Já a média total da carga viral dos pacientes antes de iniciarem a terapia foi de 116.462 cópias, sendo o menor valor 2.272 e o maior 500.000 (gráfico 6).

Gráfico 6 - Valores da Carga Viral de Cada Paciente por Ordem Crescente de Idade Antes do Início da Terapia Antirretroviral

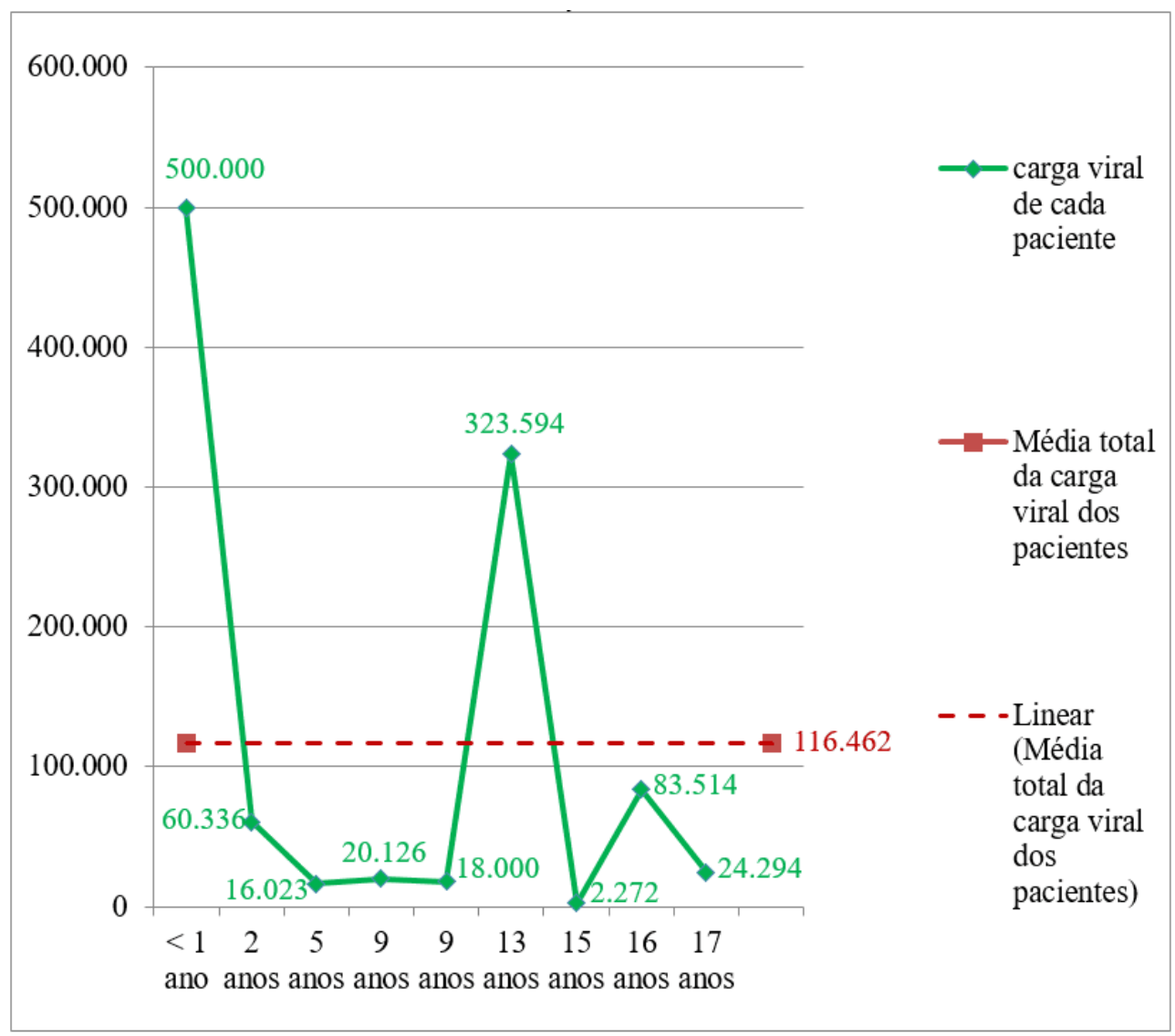


Fonte: Produção própria

Baseado nos dados acima, a maioria dos pacientes, isto é, $66,66 \%$ deles, iniciou o tratamento com cargas virais entre 15.000 e 100.000 cópias, sendo que apenas 2 $(22,2 \%)$ apresentavam cargas elevadas acima de 300.000 , e somente $1(11,1 \%)$ possuía cargas abaixo de 5.000 cópias.

Após o tratamento, apenas 3 pacientes $(33,3 \%)$ conseguiram negativar suas cargas virais $(C V=0)$, dos quais 1 evoluiu para óbito devido coinfecção com tuberculose miliar e outras doenças associadas. Enquanto os 6 restantes $(55,5 \%)$ mantiveram, após 6 meses de tratamento, uma média total de 9.484 cópias virais, sendo o menor valor 681 e o maior 56.939, como demonstrado abaixo (gráfico 7).

Gráfico 7 - Valores da Carga Viral de Cada Paciente por Ordem Crescente de Idade Após o Início da Terapia Antirretroviral

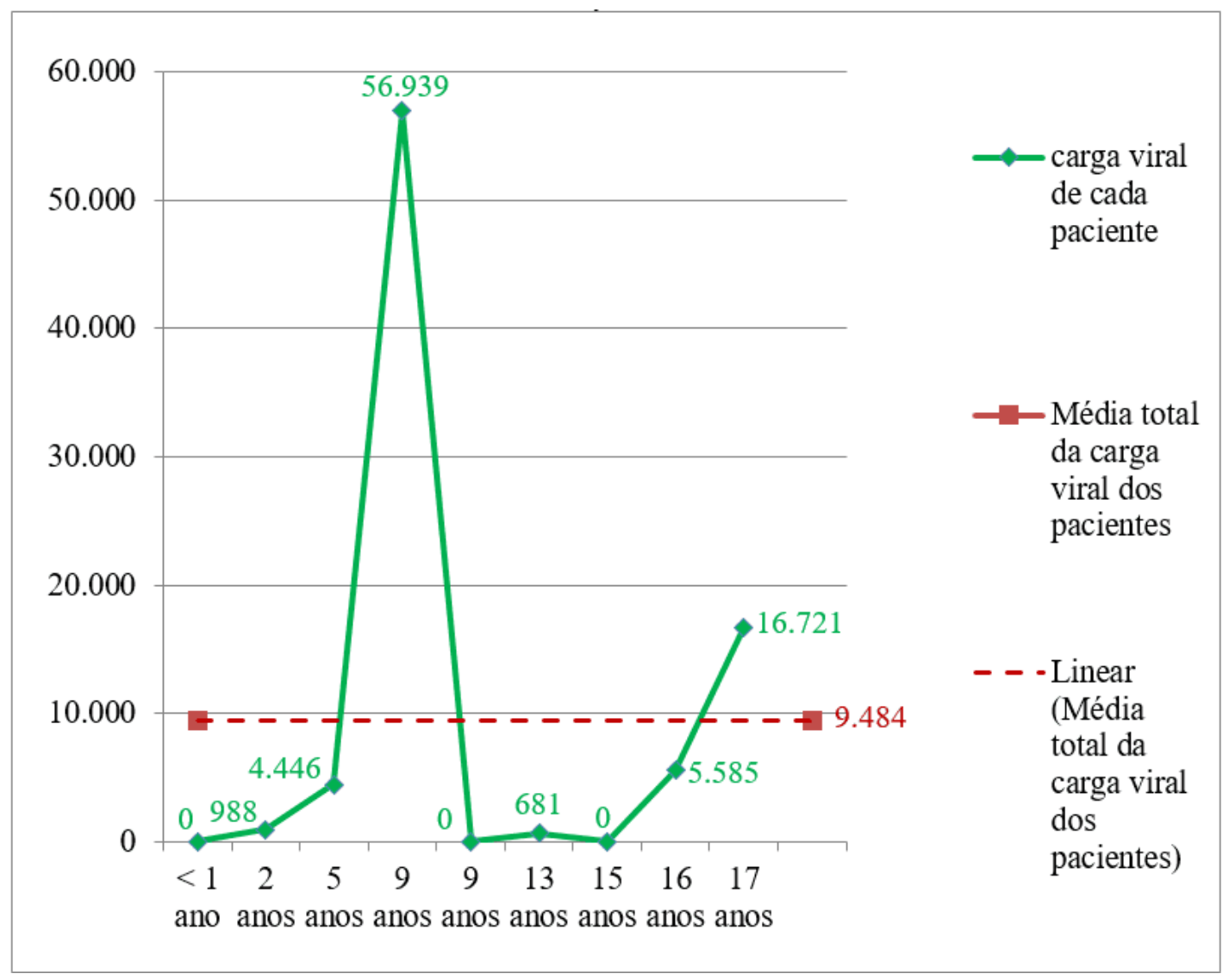

Fonte: Produção própria 
Embora as cargas virais tenham diminuído bastante comparadas com as iniciais, os valores detectados, com exceção dos negativados $(C V=0)$, não são suficientes para a meta terapêutica. De acordo com o Ministério da Saúde, "uma carga viral $>400$ cópias/mL de RNA do HIV após 6 meses de tratamento, ou qualquer detecção por métodos mais sensíveis após 12 meses de tratamento (i.e., carga viral $>50$ cópias $/ \mathrm{mL}$ de RNA do HIV)" indicam uma resposta terapêutica incompleta, consistindo em falha terapêutica virológica."Episódios esporádicos de detecção de cargas virais baixas (< 1.000 cópias/ $\mathrm{mL}$ ) são comuns e não refletem necessariamente falha virológica. Por outro lado, cargas virais repetidamente detectadas (> 1.000 cópias $/ \mathrm{mL}$ ) geralmente representam rebote e falha" ${ }^{11}$, o que consiste o caso desses pacientes, visto que apresentaram mais de um exame positivo nos últimos 12 meses.

Já a média total dos valores de CD4+ dos pacientes, após o tratamento, foi de 797,556 , sendo o menor valor 72 e o maior 1.565 (gráfico 8).

Gráfico 8 - Valores de Linfócitos T CD4+ de Cada Paciente por Ordem Crescente de Idade Após o Início da Terapia Antirretroviral

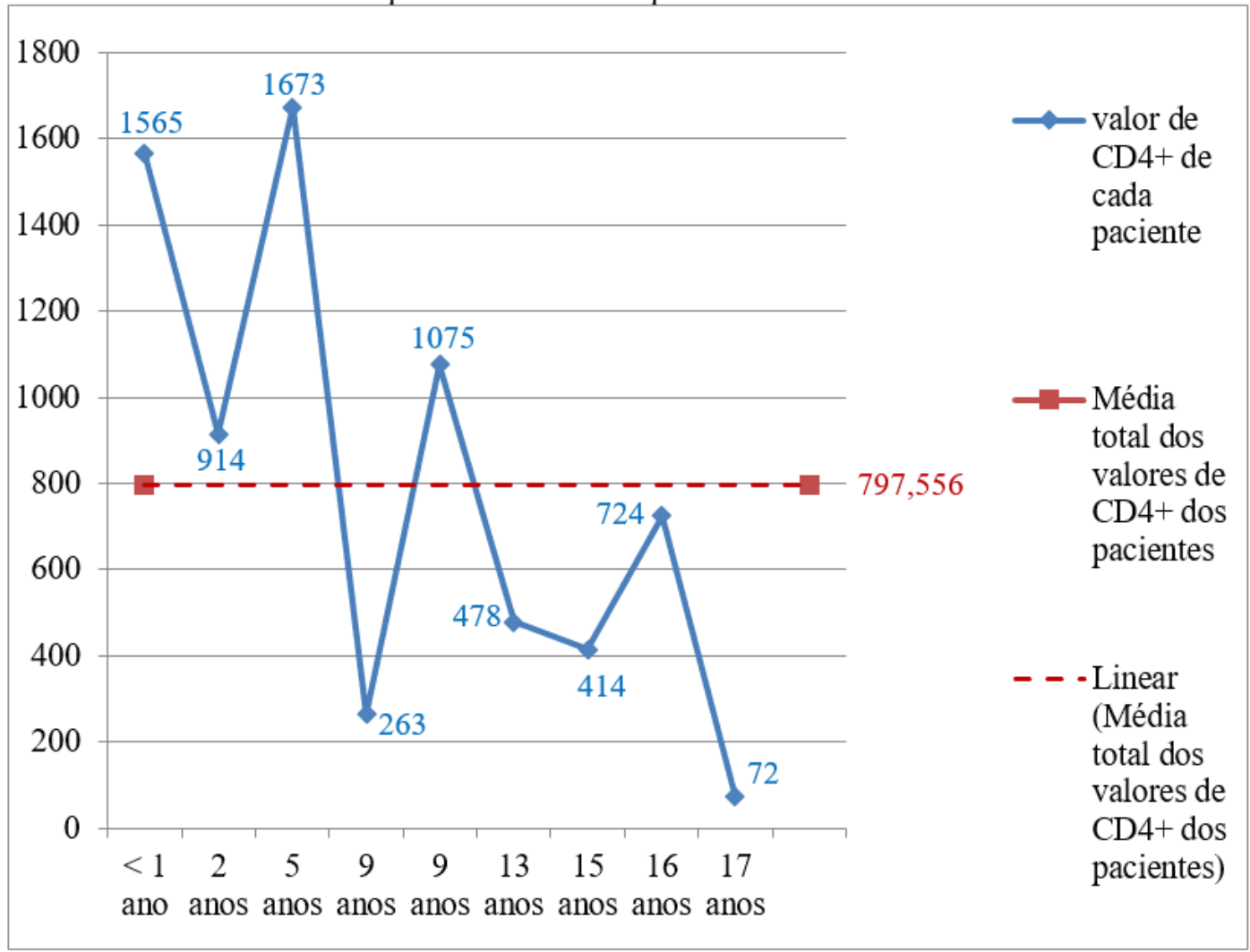


Fonte: Produção própria

Baseado nos dados acima, 4 pacientes conseguiram atingir uma imunidade satisfatória, enquanto 4 não obtiveram mudanças significativas e 1 apresentou deterioração imunológica. De acordo com o Ministério da Saúde, "considera-se deterioração imunológica a ocorrência de uma queda persistente de $5 \%$ na contagem de CD4+ em crianças de qualquer faixa etária e/ou uma redução do número absoluto basal em crianças maiores de 5 anos de idade" ${ }^{11}$, queda, esta, apresentada pelo adolescente de 17 anos.

Ao se comparar os valores de carga viral com os de CD4+, é possível perceber que dos 4 pacientes (44,44\%) que apresentaram boa resposta imunológica, 2 não conseguiram negativar sua carga viral, enquanto que dos 5 pacientes restantes $(55,5 \%)$, com resposta imunológica pequena ou nula, 4 apresentaram altas taxas de carga viral. Conclui-se, portanto, que 6 pacientes não atingiram a meta terapêutica. Entretanto, ao investigar melhor os prontuários, percebe-se que tal fato não se deve a uma falência medicamentosa, mas, sim a uma falha na aderência dos pacientes ao tratamento. Para alguns pesquisadores, a não adesão à TARV está significativamente relacionada: à idade, às baixas condições socioeconômicas dos doentes, ao esquema de medicamentos; além da relação interpessoal com os profissionais de saúde. ${ }^{12,13}$ De acordo com um estudo realizado no Rio de Janeiro, conclui-se que as fases iniciais são as mais vulneráveis para a não aderência, sendo identificados também como fatores de abandono terapêutico: a falta de uma rede social de apoio, e determinados hábitos de vida dos pacientes, como o uso de drogas e antecedentes psiquiátricos. ${ }^{12}$ Com relação às crianças, estudos apontam para algumas dificuldades na utilização da TARV pelos cuidadores, tais como: apresentação dos medicamentos, efeitos colaterais, horário de administração deles, acesso ao serviço, recursos financeiros limitados e aspectos socioculturais. Ademais, a maioria dos cuidadores apresentam baixo nível de escolaridade, se encontrando em condição de vulnerabilidade social e com grau de instrução limitado, o que dificulta o processo de educação em saúde no cuidado especial a essas crianças com HIV. O fato do SUS fornecer acesso gratuito à medicação é fundamental para a adesão ao tratamento, entretanto, além disso, 
também é essencial a atuação de uma equipe multidisciplinar e sua responsabilidade conjunta na definição de estratégias terapêuticas e desenvolvimento de suporte ao longo do tratamento, oferecendo, principalmente, informações claras aos cuidadores, visto que o êxito terapêutico também depende da correta compreensão a respeito da doença e de seu tratamento. ${ }^{6,14,15}$ Além disso, "a escuta dos contextos individuais favorece uma abordagem mais resolutiva. [...] Valorizar suas histórias de vida e vivências, além de incluí-las no próprio cuidado, são fatores essenciais para a efetividade do tratamento." " $A$ Anda em relação a esse tema, a OMS, em colaboração com organizações parceiras, tem investido no desenvolvimento de medicamentos com combinações em dose fixa apropriadas para crianças, como o dolutegravir ou o TAF.31, com o intuito de otimizar o tratamento nessa faixa etária, facilitando a adesão. ${ }^{16}$

Outro dado avaliado foi a respeito das internações dos pacientes, sendo que apenas $33,3 \%$ deles não necessitaram de internação, ao contrário dos outros $66,6 \%$, cujas causas variaram bastante. Dentre elas, se encontram: queda da imunidade, grande emagrecimento em pouco tempo, pneumonia, pneumocistose, cefaleia em região frontal e supraorbital bilateralmente, cólica renal e infecção urinária, desidratação, além de outras causas como a administração de imunoglobulina endovenosa, e a necessidade de exames de urgência.

E por fim, analisaram-se as infecções associadas dos pacientes, sendo as mais prevalentes, atingindo $77,77 \%$ dos casos: as infecções de vias aéreas superiores, tais como: tosse sem ou com expectoração, coriza, orofaringe hiperemiada, otite, além das pneumopatias. Em segundo lugar, abrangendo $44,44 \%$ dos indivíduos, ficaram as afecções dermatológicas, como: dermatite, onicomicose, granuloma, e principalmente as lesões máculopapulo-eritematosas, que são as mais frequentes. Outras patologias prevalentes foram: doenças fungicas, parasitárias (giardíase, toxoplasmose) e herpes zoster, todas abrangendo $33,3 \%$ dos pacientes. Enquanto que fraqueza, febre, linfadenopatia cervical, varicela, diarreia, vômito, odinofagia, doenças bacterianas e abcesso axilar ou facial envolveram $22,2 \%$ dos pacientes cada; e sífilis, bronquite, pneumocistose, dispneia, anorexia, caxumba, nódulos axilares ou inframandibulares, 
parotidite, tuberculose, hepatoesplenomegalia, artrite reacional e furúnculo foram as menos encontradas, equivalendo a $11,1 \%$ dos pacientes cada. Todos esses quadros ocorreram em vigência de altas taxas de carga viral, o que reforça novamente a importância do controle precoce da doença, mesmo em pacientes assintomáticos, a fim de se evitar as infecções oportunistas, reduzindo a morbimortalidade e a progressão da doença e consequentemente, promovendo uma melhor qualidade de vida aos pacientes. ${ }^{6,9,10}$

\section{CONSIDERAÇÕES FINAIS}

Através dessa pesquisa realizada, concluímos que $88,8 \%$ das crianças e adolescentes HIV positivos que passaram pelo CADIP, desenvolveram a doença por transmissão vertical. Tal análise reforça, portanto, a importância da implementação de "medidas de prevenção primária que envolvam educação, informação, prevenção e/ou tratamento precoce de DST's, prevenção da gravidez não planejada, além da disponibilidade de aconselhamento", e acesso efetivo aos testes de detecção do HIV; com o intuito de se eliminar a transmissão perinatal da doença como problema de saúde pública. Ademais, a realização do acompanhamento pré-natal regularmente associado a um parto seguro e ao uso correto dos antirretrovirais são medidas que também fazem parte dessa luta da OMS. ${ }^{8}$

É válido ainda ressaltar sobre a importância do inicio precoce da TARV em crianças e adolescentes, mesmo que assintomáticos, uma vez que o controle prévio do HIV diminui a mortalidade infantil precoce e previne a progressão da doença, de forma a promover uma melhor qualidade de vida aos pacientes associada a uma maior sobrevida. Além disso, é essencial, nessa faixa etária, se atentar à não adesão ao tratamento, que ainda corresponde o principal obstáculo para o sucesso terapêutico.

\section{REFERÊNCIAS}

1. MINISTÉRIO DA SAÚDE. Protocolo clínico e diretrizes terapêuticas para manejo da infecção pelo HIV em crianças e adolescentes. Brasília, DF, 2014. 238 p. 23-25 Disponível em: <http://www.aids.gov.br/pt-br/pub/2014/protocolo- 
clinico-e-diretrizes-terapeuticas-para-manejo-da-infeccao-pelo-hiv-emcriancas-e>. Acesso em: 6 maio 2019

2. SECRETARIA DE VIGILÂNCIA EM SAÚDE, MINISTÉRIO DA SAÚDE. DEPARTAMENTO DE DOENÇAS SEXUALMENTE TRANSMISSÍVEIS, AIDS E HEPATITES VIRAIS. Boletim epidemiológico HIV/Aids. Brasília, DF, 2016, p. 13-14 Disponível em: $<$ http://www.aids.gov.br/ pt-br/pub/2016/boletim-epidemiologico-de-aids-2016>. Acesso em: 07 maio 2019

3. DIAS, Jucelma de Jesus. Sobrevida e fatores associados ao óbito em crianças, adolescentes e adultos jovens soropositivos para hiv por transmissão vertical. 2015, 88f. p. 22 e p. 30 Dissertação (mestrado em saúde coletiva) Universidade Estadual de Feira de Santana, Feira de Santana, BA, 2015. Disponível em: <http://tede2.uefs.br:8080/bitstream/tede/357/2/ Disserta\%C3\%A7\%C3\%A30\%20vers\%C3\%A3o\%20final\%20p\%C3\%B3s\%20 defesa.pdf>.

Acesso em: 07 maio 2019

4. NEGRA, Marinella Della; QUEIROZ, Wladimir; LIAN, Yu. Ching. Aids pediátrica. In: FOCACCIA, R.; VERONESI, R. Tratado de Infectologia. 5. ed. São Paulo: Editora Atheneu, 2015. cap. 9.6, p. 260-261

5. MINISTÉRIO DA SAÚDE. "Aids: etiologia, clínica, diagnóstico e tratamento" Unidade de assistência. Brasília, 2002. p. 10-16 Disponível em: <http://bvsms.saude.gov.br/

bvs/publicacoes/Aids_etiologia_clinica_diagnostico_tratamento.pdf>. Acesso em: 10 maio 2019

6. MINISTÉRIO DA SAÚDE. Protocolo Clínico e Diretrizes Terapêuticas para Manejo da Infecção pelo HIV em Crianças e Adolescentes. Brasília, DF, 2018, 213 p. Disponível em: <http://www.aids.gov.br/ pt-br/pub/2017/protocolo-clinico-e-diretrizes-terapeuticas-para-manejo-dainfeccao-pelo-hiv-em-criancas-e>. Acesso em: 10 maio 2019

7. RUBINI, Norma. Alterações imunológicas em crianças com infecção pelo HIV. Jornal de Pediatria, Rio de janeiro, 1999, v. 75, n. 3, p. 147-148. Disponível em: 
<http://www.jped.com.br/conteudo/99-75-03-147/port_print.htm>. Acesso em: 10 maio 2019

8. RIBEIRO, Ana Freitas; VERAS, Maria Amélia de Sousa Mascena; GUERRA, Maria Aparecida Telles. Epidemiologia da Infecção pelo HIV/aids. In: FOCACCIA, R.; VERONESI, R. Tratado de Infectologia. 5. ed. São Paulo: Editora Atheneu, 2015. cap. 9.2, 183.

9. INSIGHT START STUDY GROUP. Initiation of Antiretroviral Terapy in Early Asymptomatic HIV Infection. The New England Journal of Medicine, [S.I.], v. 373, p. 795-807, Aug. 2015. Disponível em: <https://www.nejm.org/doi/full/10.1056/NEJMoa1506816>. Acesso em: 17 ago. 2019

10. VIOLARI, Avy, et al. Early antiretroviral therapy and mortality among HIVinfected infants. The New England Journal of Medicine, v. 359, n. 21, p. 22332244, Nov. 2008.2 Disponível em: <https://www.nejm.org/doi/full/10.1056/NEJMoa0800971>. Acesso em: 25 jul 2019

11. MINISTÉRIO DA SAÚDE, Recomendações para Terapia Antirretroviral em Crianças e Adolescentes Infectados pelo HIV 2009. Brasília, DF 2012, p.8-10 Disponível em: <http://bvsms.saude.gov.br/ bvs/publicacoes/recomendacoes_antiretroviral_criancas_hiv_2009_suplement o_2.pdf>. Acesso em: 30 jul. 2019

12.SCHILKOWSKY, Louise Bastos; PORTELA, Margareth Crisóstomo; SÁ, Marilene de Castilho. Fatores associados ao abandono de acompanhamento ambulatorial em um serviço de assistência especializada em HIV/aids na cidade do Rio de Janeiro, RJ. Revista Brasileira de Epidemiologia, São Paulo, fev. 2011; vol. 14, n. 2, p. 187-97 Disponível em: <http://www.scielo.br/pdf/rbepid/v14n2/01.pdf>. Acesso em: 15 agos. 2019.

13. BRITO, Ana Maria de; SZWARCWALD, Célia Landmann; CASTILHO, Euclides Ayres de. Fatores associados à interrupção de tratamento anti-retroviral em adultos com aids. Rio Grande do Norte, Brasil, 1999-2002. Revista Associação de Médicos Brasileiros, 2006, v. 52, n. 2, p. 86-92. Disponível em: $<$ https://www.arca.fiocruz.br/ 
bitstream/icict/631/2/LANDMANN_TRATAMENTO\%20ANTI\%20RETROVIRA L\%20RN_2006.pdf>. Acesso em: 28 jul. 2019

14. FEITOSA, Ana Claúdia; et al. Terapia anti-retroviral: fatores que interferem na adesão de crianças com HIV/aids. Escola Anna Nery Revista de Enfermagem. Rio de Janeiro, set. 2008, v. 12, n. 3, p. 515-521. Disponível em: <http://www.scielo.br/pdf/ean/v12n3/v12n3a18>. Acesso em: 25 jul. 2019

15. KATABIRA Elly Tebasoboke. Assistência em hiv/aids. Associação Brasileira Interdisciplinar de AIDS - ABIA. Rio de janeiro, p. 1-3. Disponível em: $<$ http://bvsms.saude.gov.br/bvs/periodicos/acao_anti_aids43.pdf>. Acesso em: 15 ago 2019

16. UNAIDS, Programa Conjunto das Nações Unidas sobre HIV/AIDS. 90-90-90 Uma meta ambiciosa de tratamento para contribuir para o fim da epidemia da AIDS. Suiça, nov. 2015, p. 15 Disponível em: <https://unaids.org.br/wpcontent/uploads/2015/11/2015_11_20_UNAIDS_TRATAMENTO_META_PT_ v4_GB.pdf>. Acesso em: 17 ago. 2019

Enviado: Janeiro, 2020.

Aprovado: Janeiro, 2020. 